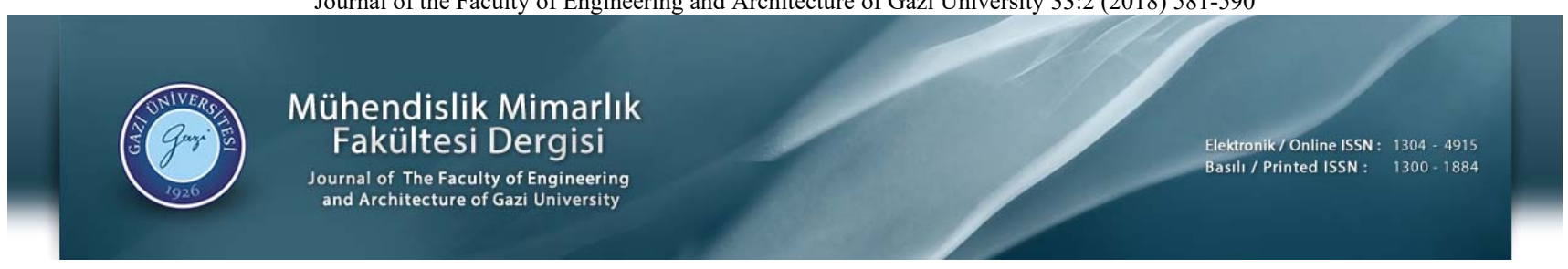

\title{
Farklı mineral katkıların epoksi zemin kaplama malzemesinin ıslanmazlığına ve yüzey enerjisine etkisi
}

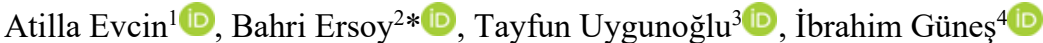 \\ ${ }^{1}$ Afyon Kocatepe Üniversitesi, Mühendislik Fakültesi, Malzeme Bilimi ve Mühendisliği Bölümü, 03200, Afyonkarahisar, Türkiye \\ ${ }^{2}$ Afyon Kocatepe Üniversitesi, Mühendislik Fakültesi, Maden Mühendisliği Bölümü, 03200, Afyonkarahisar, Türkiye \\ ${ }^{3}$ Afyon Kocatepe Üniversitesi, Mühendislik Fakültesi, İnşaat Mühendisliği Bölümü, 03200, Afyonkarahisar, Türkiye \\ ${ }^{4}$ Afyon Kocatepe Üniversitesi, Teknoloji Fakültesi, Metalurji ve Malzeme Mühendisliği Bölümü, 03200, Afyonkarahisar, Türkiye
}

\section{Ö N E C I K A N L A R}

- $\quad$ Polimerik zemin kaplama malzemesinin ıslanmazlığına ve yüzey enerjisine mineral katkı türü ve miktarının etkisi incelenmiştir

- Mineral katkı olarak uçucu kül, silis dumanı, yüksek firın cürufu ve kireçtaşı kullanılmıştır

- Epoksinin hidrofobik karakterini en çok azaltan katkı türü kireçtaşı iken en az azaltan uçucu kül olmuştur

Makale Bilgileri

Gelis: 24.11.2016

Kabul: 18.08.2017

DOI:

$10.17341 /$ gazimmfd.416368

Anahtar Kelimeler:

Epoksi, mineral atık,

kompozit,

hidrofobisite,

yüzey enerjisi,

temas açısı

\section{ÖZET}

Bu çalışmada epoksi esaslı zemin kaplama malzemesinin ıslanmazlık ve yüzey enerjisi üzerine mineral katkı türü ve miktarının etkisi incelenmiştir. Mineral katkı olarak üç farklı atık ürün (uçucu kül, silis dumanı ve yüksek firın cürufu) ile kireçtaşı kullanılmıştır. Üretilen her bir katkılı ve katkısız epoksi malzemesinin 1slanmazlık özelliğinin belirlenmesinde, damla yayınım (sessile drop) yöntemi kullanılarak su ile temas açıları ölçülmüștür. Epoksi malzemelerin yüzey enerjisi hesaplamaları için ise 3 polar sıvı su, etilen glikol ve formamid ile 1 apolar sıvı diiodometan kullanılarak temas açıları ölçülmüş ve sonra bu temas açısı verilerine göre Fowkes yaklaşımı kullanılarak yüzey enerjileri hesaplanmıştır. Elde edilen sonuçlara göre, mineral katkılar az ya da çok epoksinin islanmazlık özelliğini düşürmekte ve buna uygun olarak yüzey enerjisini artırmaktadır. Katkı türleri içerisinde epoksinin ıslanmazlık ve yüzey enerjisi özelliklerine en az etki edenin uçucu kül ve en çok etki edenin ise kireçtaşı olduğu belirlenmiştir.

\section{The effect of different mineral additives on non-wettability and surface energy of epoxy floor coating}

\section{H I G H L I G H T S}

- The effect of type and amount of mineral additives on hydrophobicity and surface energy of polymeric material have been examined

- Fly ash, fume silica, blast furnace slag and limestone were used as mineral additive

- While the highest decreasing on hydrophobicity of epoxy is obtained by limestone, the lowest decreasing is obtained by using fly ash

Article Info

Received: 24.11 .2016

Accepted: 18.08 .2017

DOI:

10.17341/gazimmfd.416368

Keywords:

Epoxy,

mineral waste, composite,

hydrophobicity,

surface energy,

contact angle

\section{ABSTRACT}

In this study, the effect of type and amount of mineral additives on non-wettability and surface free energy of epoxy based floor coating material have been examined. Three different types of waste products (fly ash, fume silica and blast furnace slag) and limestone were used as mineral additive. Contact angle with water of each produced epoxy material with and without additive were measured by using sessile drop method to determine the hydrophobicity of the materials. For surface energy calculations of epoxy materials, their contact angles first were measured by using three polar (water, ethylene glycol and formamide) and one apolar (diiodomethane) liquid and their surface energies were then calculated according to these contact angles data by using Fowkes approach. Test results show that mineral additives have more or less decreased the hydrophobicity and increased surface energy. It was also determined that in additives fly ash has minimum and limestone has maximum effect on hydrophobicity and surface energy properties of epoxy. 


\section{GİRIŞ (INTRODUCTION)}

Islanmazlık bir başka ifadeyle su sevmezlik (hidrofobisite) veya bunun tam tersi 1slanabilirlik yani su severlik (hidrofilisite) ve yüzey enerjisi terimleri inşaat, kimya, gida, tekstil, boya, cam, eczacilik, madencilik, elektrikelektronik, metalürji ve malzeme vb. birçok farklı endüstriyel alanlarda malzeme veya ürün üretimi sırasında karşımıza çıkmaktadır. Bunlardan bazılarını şu şekilde sıralayabiliriz: tekstilde su tutmayan yani 1slanmayan kumaş eldesinde [1]; metal endüstrisinde yapışmaz yüzey elde etmek için metal yüzeyinin teflon vb. ile kaplanmasında [2, 3]; kâğıt sektöründe kâğıt yüzeyinin boyanabilirliğinin ve baskı kalitesinin belirlenmesinde [4, 5]; madencilikte, flotasyon ile cevher zenginleştirme işleminde ve çöktürme yöntemiyle katı sıvı ayırımında [6]; gida, kozmetik ve boya endüstrisinde emülsiye haldeki ürünlerin stabilitesinin sağlanmasında [7]; eczacılıkta ilaç (hap) formülasyonlarının oluşturulmasında [8]; elektrik ve elektronik sanayiinde çip vb. elektronik devrelerin üretiminde ve yalıtım malzemesi üretiminde ürün kalitesinin belirlenmesinde $[9,10]$; inşaat sektöründe özellikle zemin sularına karşı binaların temel yapılarının korunması için hidrofobik özelliğe sahip malzemelerle kaplanmasında [11], malzeme alanında süper hidrofob ürün veya yüzey elde edilmesinde [12] ve biomalzeme üretiminde [13]. Bir katının 1slanmazlığının veya 1slanabilirliğinin belirlenmesi, o katının yüzeyine bırakılan bir su damlasının yüzey ile yaptığı açı olan temas açısına ( $\theta$ ) bağlı olarak ifade edilebilir (Şekil 1). Yüzey ne kadar hidrofilik karakterde olursa o zaman su ile yüzey arasındaki adhezyon kuvvetleri suyun kendi molekülleri arasındaki kohezyon kuvvetlerinden daha baskın hale gelir ve suyu kendine çeker ve açıyı düşürür. Sifır derecede veya buna yakın bir açıda mükemmel ıslanma gerçekleşir. Aksine, yüzey ne kadar hidrofobik yapıda olursa o zaman da sistemde su molekülleri arasındaki kohezyon kuvvetleri, su ile yüzey arasındaki adhezyon kuvvetlerinden daha baskın olur ve bu sayede su damlası yüzeyden uzaklaşarak toplanır buna 1slanmazlık durumu denir. $\mathrm{Bu}$ temas açısı $150^{\circ}$ nin üzerinde olursa buna mükemmel 1slanmazlık veya süperhidrofobik hali denir $[12,14]$.

1805 yllında ilk olarak Thomas Young tarafindan tanımlanan temas açısı ölçümleri halen daha, katıların 1slanmazlık ve yüzey enerjisi gibi yüzey özelliklerini karakterize etmede ve minimum denge uzaklığında sıv1katı arayüzey ve katı yüzey enerjisini belirlemede en basit ve en doğru metotlardan birisidir [6]. Temas açısı ( $\theta)$ 'nın yüzey ve arayüzey enerjilerine bağlı ifadesi meşhur Young eşitliği olarak da bilinmekte olup, aşağıda Eş. 1'de gösterilmiş ve Şekil 2'de şematize edilmiştir.

$\gamma_{\mathrm{SG}} \operatorname{Cos} \theta=\gamma_{\mathrm{KG}}-\gamma_{\mathrm{KS}}$

Bu eşitlikte; $\gamma_{\mathrm{SG}}$ : Sıvının yüzey gerilimi (enerjisi) $\left(\mathrm{mJ} / \mathrm{m}^{2}\right)$ $\gamma_{\mathrm{KS}}:$ Kat1 - sıv1 arayüzeyinin enerjisi $\left(\mathrm{mJ} / \mathrm{m}^{2}\right), \gamma_{\mathrm{KG}}$ : Kat1 yüzeyinin enerjisi $\left(\mathrm{mJ} / \mathrm{m}^{2}\right)$
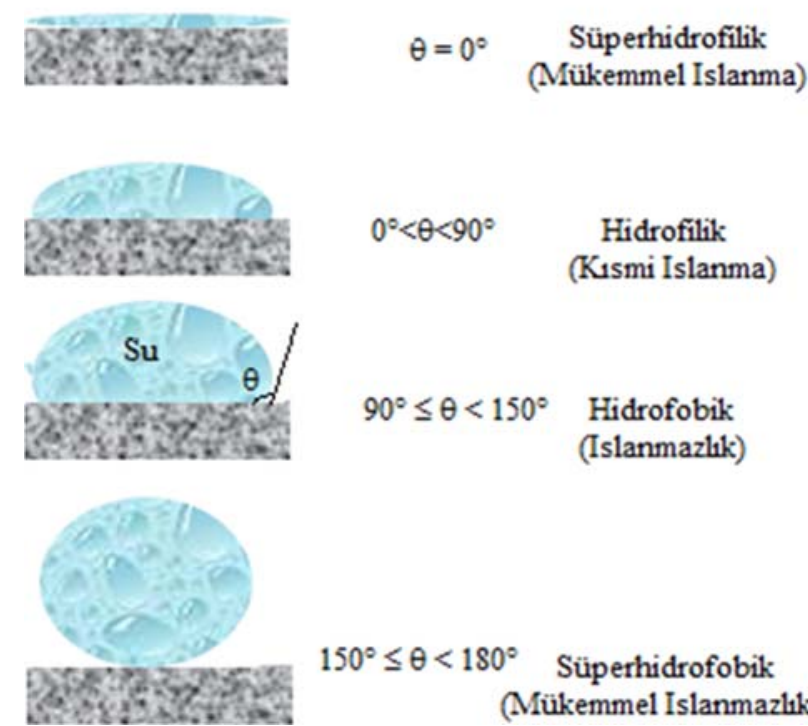

$0^{\circ}<\theta<90^{\circ}$

Hidrofilik

(Kısmi Islanma)

$90^{\circ} \leq \theta<150^{\circ} \quad$ Hidrofobik

(Islanmazlik)

\section{$150^{\circ} \leq \theta<180^{\circ} \quad$ Süperhidrofobik}

(Mükemmel Islanmazlik)

Şekil 1. Bir su damlasının katı yüzeyi ile yaptığı farklı temas açıları ve buna bağlı 1slanmazlık durumu

(Contact angle between a water drop and a solid surface and depending on this non-wettability situation)

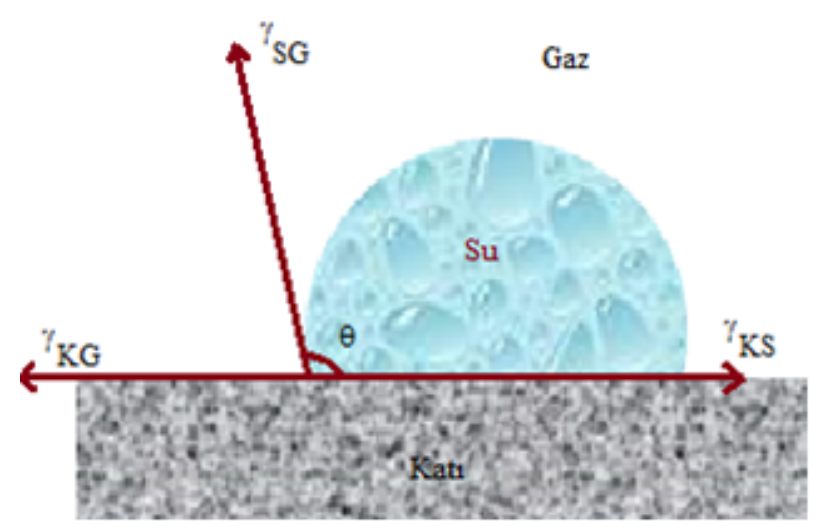

Şekil 2. Bir sıvı (su) damlasının, sistemdeki yüzey ve arayüzey enerjilerine bağlı olarak bir katı yüzeyi ile yaptığı temas açısının $(\theta)$ şematik gösterimi

(Depending on surface and interface energies in system schematic represantation of contact angle between a liquid (water etc.) drop and solid surface)

Bir yoğun faz (katı veya sıvı) ile gaz fazı arasındaki bölge yüzey olarak adlandırılır. Örneğin Kat1-Hava arayüzeyi katı yüzeyi olarak adlandırılır. Arayüzey ise temas halindeki iki yoğun faz arasındaki bölgeye denir, mesela katı bir yüzey üzerinde duran bir su damlas1 kat1-sıv1 arayüzeyini oluşturur. Arayüzeyin fiziksel ve kimyasal özellikleri kendisini oluşturan her iki fazdan da farklıdır [6,7]. Çıplak gözle dışarıdan bakıldığında çok düzgün gözüken bir katı malzemenin yüzeyine elektron mikroskop ile atomik ölçekte bakıldığında, mükemmellikten veya homojenlikten uzak lokal bir takım noktasal, çizgisel veya düzlemsel 
hatalar içeren kristal düzlemlerine, çeşitli oyuk ve boşluklara, malzemenin iç kısımlarında olmayan kenar ve köşelere sahip olduğu görülebilir. Ayrıca yüzeydeki atomlar malzemenin iç kısmındaki atomlara göre daima dengelenmemiş kuvvetler ihtiva eder ki bunun da sebebi yüzeyde kırılmış/kopmuş veya zayıflamış kimyasal bağlardır. Tüm bu sebepler malzeme yüzeyinde bir enerji fazlalığına yol açar ki buna katının serbest yüzey enerjisi veya kısaca yüzey enerjisi denir [15, 16]. Malzemeler düşük ve yüksek yüzey enerjili olarak iki gruba ayrılabilir. Mesela hidrofobik özelliğe sahip polimerik malzemeler (Polyester, naylon, teflon vb.), wax ve organik esaslı malzemelerin çoğu düşük yüzey enerjili olup yüzey enerjileri genellikle $100 \mathrm{~mJ} / \mathrm{m}^{2}$ 'nin altındadır [17, 18]. Buna mukabil hidrofilik özelliğe sahip metal, cam ve seramik malzemeler yüksek yüzey enerjisine sahip olup yüzey enerjileri genellikle $500-5000 \mathrm{~mJ} / \mathrm{m}^{2}$ arasındadır [17, 19]. Çeşitli işlemler uygulayarak malzemelerin sslanmazlık özelliğini ve yüzey enerjisini değiştirebilmek mümkündür. Bunları şu şekilde sıralayabiliriz; malzeme yüzeyinin asitle veya 1 sil işlemle muamale edilmesi $[6,16]$, kesme, aşındırma, parlatma vb. işlem uygulanması [21], yüzeyin gaz, nem veya yüzey aktif madde adsorpsiyonuna maruz bırakılması [6], malzemenin öğ̈̈tülmeye tabi tutulması [20] ve yüzeyin yağlanması veya yüzeye çeşitli kaplama işleminin uygulanması (mesela teflon kaplama, waxlama, kumlama gibi) [17, 21]. Yüzey enerjisi ile hidrofobisite arasındaki ilişki kabaca şu şekildedir: Bir katının yüzeyinin hidrofobisitesi arttıkça yüzey enerjisi azalır veya tersi hidrofobisitesi azaldıkça yüzey enerjisi artar [18]. Polimer veya polimerik matrisli kompozit malzemelerin en önemli özelikleri su, 1sı ve elektriği geçirmemeleri, çok düzgün yüzeylere sahip olmaları, asite dayanıklı ve hafif bir malzeme olmalarıdır [22, 23]. Bu nedenle bu tür malzemeler özellikle uzay/havacılık, elektrik, elektronik, inşaat, gemi ve otomobil sanayi gibi bir çok endüstriyel alanda yaygın kullanım alanına sahiptir [24]. Epoksi esaslı polimerik malzemeler genellikle elektrik sektöründe kablo ek yerlerinin atmosfer koşullarından korunması, iletken etrafındaki plastiklerin yapımı gibi yalıtım amaçlı malzemelerin üretiminde oldukça yaygın kullanılmaktadır $[10,25]$. Ancak son y1llarda epoksi esasli ve mineral (kalsit, kuvars vb.) katk1lı kompozitler inşaat sektöründe zemin kaplama malzemesi olarak da kullanılmaya başlanmıştır. Bu tür malzemeler, zemin üzerinde kendiliğinden yayılma (yerleşme) özeliğine sahip olan, mekanik dayanımı yüksek, farklı kimyasal ve sıcaklık şartlarına dayanımlı, üç boyutlu işlenebilen ve albenisi olan homojen bir yapı malzemesidir. $\mathrm{Bu}$ tür zemin kaplama malzemelerinin bir diğer özelliği de asit, yağ ve kirden etkilenmeyişi ve su geçirmez olmalarıdır. Buna bağlı olarak da hijyenik oldukları belirtilir [26, 27]. Literatürde teflon, polyester, polimetilmetakrilat, naylon, epoksi vb. farklı tür polimerlerin yüzey enerjilerinin ve hidrofobik özelliğinin belirlenmesi üzerine çok sayıda çalışma yapılmış olup, polimerik malzemelerin düşük yüzey enerjisine (genellikle $10-70 \mathrm{~mJ} / \mathrm{m}^{2}$ ) sahip 1slanmaz (genellikle $\theta>90^{\circ}$ ) karakterde katılar olduğu açıç̧a ispat edilmiştir [28, 29]. Ancak, yazarların araştırdığı kadarıyla farklı tiplerde mineral katk1 içeren epoksi zemin kaplama malzemesinin 1slanabilirliğinin incelenmesi ve yüzey enerjilerinin belirlenmesi üzerine pek çalışma yapılmamıştır. Syakur vd. (2012) epoksiye silikon kauçuk ve silis kumu katarak hidrofobik karakterini ve elektrik izolasyon kabiliyetini incelemişler ve sonuçta silikon kauçuğun her iki özelliği de pozitif yönde artırırken, epoksiye ağırlıkça \%10-20 silika katkısının bu özellikler üzerine bir etkisinin olmadığını belirlemişlerdir [10]. Atta vd (2016) yüzeyi yă̆ asitleriyle modifiye edilmiş $\mathrm{CaCO}_{3}$ nanopartikül içeren epoksi kaplamaların su ile temas açılarını ölçmüşler ve modifiye kalsit ilavesiyle temas açısının ciddi oranda arttığını belirlemişlerdir [30]. Ancak burada şunu belirtmekte fayda var: Kalsit minerali esasen doğal halde hidrofilik yapıda olup [31], yüzeyi yüzey aktif maddeler ile kaplanarak hidrofobik hale getirilebilmektedir. Diğer yandan ülkemizde her y1l ciddi miktarda mineral atık madde ortaya çıkmaktadır. Örneğin demir çelik üretim tesislerinden ortaya çıkan yüksek firın cürufu, termik santrallerde kömür yakılması sonrası ortaya çıkan uçucu kül, elektrometalürji tesislerinden ortaya çıkan silis dumanı, bu tür katı atıkların başında gelmektedir. Büyük miktarlarda oluşan bu katı atıkların çok az bir kısmı bazı sektörlerde değerlendirilmektedir. Mesela ülkemizde katı atık olarak ortaya çıkan uçucu kül miktarı yılda yaklaşık 13 milyon ton olup, bunun ancak \%1'lik kısmı çimento-beton sanayiinde kullanılmak üzere geri kazanılabilmektedir [32]. Bu tür atıkların büyük bir bölümü verimli arazilere terk edilerek hem çevre kirliliği oluşturmakta hem de araziler verimsiz hale gelmektedir. Bu çalışmanın temel amacı, günümüzde kullanımı gittikçe yaygınlaşmakta olan epoksi esaslı zemin kaplama malzemesinin iki temel yüzey özelliğinin (1slanmazlık ve yüzey enerjisi) atık haldeki farklı tür mineral katkılar ile ne şekilde değiştiğini incelemektir. Diğer bir amaç ise elde edilecek sonuca göre, bu atıl durumdaki atıkların, kaynaklarımızın geri dönüşümüne katkı sağlayabilmektir.

\section{MALZEMELER VE YÖNTEMLER (MATERIALS AND METHODS)}

\subsection{Kullanılan Malzemeler ve Özellikleri \\ (Materials Used and Their Properties)}

\subsubsection{Epoksi ve mineral katkllar (Epoxy and mineral additives)}

Polimer esaslı zemin kaplamalarının karakteristik özelliklerinin belirlenmesi amaciyla numunelerin üretimlerinde A ve B olarak iki bileşenden oluşan genel amaçlı epoksi kullanılmış olup, kimyasal yapısı Şekil 3'de ve teknik özellikleri Tablo 1'de verilmiştir. Kireçtaşı tozu Afyonkarahisar'da bulunan Kolsan Hazır Beton Tesislerinden alınmıştır. Uçucu kül ve silis dumanı sırasıyla Tunçbilek Termik Santrali ve Etibank Antalya Elektrometalurji Sanayi İşletmesi'nden temin edilmiştir. Yüksek firın cürufu ise Bolu Çimento'dan getirilmiştir. Tüm bu mineral katkılar firma ya da kuruluşlardan toz boyutunda temin edilmiştir. Mineral katkıların kimyasal analizi (Rigaku marka ZSX Primus-2 model XRF cihazı) ile gerçekleştirilmiş olup sonuçlar Tablo 2'de verilmiştir. 
$\mathrm{Bu}$ tabloda ayrıca mineral katkılara ait özgül ağırlık ve yüzey alanı değerleri de verilmiştir. Özgül yüzey alanı ölçümlerinde silis dumanı için BET (Micromeritics Gemini 2360) cihazı kullanılırken diğer mineral katkılar için Blaine cihazı kullanılmıştır. Tablo 3'de verilen mineral katkıların tane boyut analiz değerleri incelendiğinde, Tablo 2'deki özgül yüzey alanı değerlerini doğrular nitelikte olduğu görülmektedir. Örneğin, tane dağılımında en ince malzeme yüksek firın cürufu ve silis dumanı iken, özgül yüzey alanı açısından da en yüksek değerlere yine yüksek firın cürufu ve silis dumanı sahiptir. Mineral katkıların mineralojik analizi X-ışınları difraksiyonu (XRD) yöntemiyle Shimadzu marka XRD-6000 model XRD cihazında gerçekleştirilmiş olup elde edilen difraktogramlar Şekil 4 'de verilmiştir. Buna göre, yüksek firın cürufunun ağırlıklı olarak kalsit, hematit ve feldspat minerallerinden oluştuğu<smiles>CC(=O)c1ccc(C(C)(C)c2ccc(OCC(C)(C)c3ccc(OCC4CO4)cc3)cc2)cc1</smiles>

Şekil 3. Polimer malzemelerin üretiminde kullanılan epoksi reçinesinin kimyasal yapısı [n=2-7] [33] (Chemical structure of epoxy resin used in production of polymer materials)

Tablo 1. Epoksi reçinenin teknik özelikleri (Technical properties of epoxy resin)

\begin{tabular}{ll}
\hline Renk & Saydam \\
\hline Yoğunluk & $(\mathrm{A}): 1,15 \mathrm{gr} / \mathrm{cm}^{3}(\mathrm{~B}): 1,05 \mathrm{gr} / \mathrm{cm}^{3}$ \\
Alevlenme noktası & $180^{\circ} \mathrm{C}$ \\
Karışım oranı & $2: 1$ \\
Uygulama ömrü & 45 dakika $\left(+20^{\circ} \mathrm{C}\right)$ \\
Tam mukavemet & 7 gün \\
Ambalaj & $15 \mathrm{~kg}$ 'lık set halinde \\
Raf ömrü & tçılmamış orijinal ambalajında 12 ay $5^{\circ} \mathrm{C}$ nin üzerinde saklanmalı \\
\hline
\end{tabular}

Tablo 2. Mineral katkıların kimyasal analizi, özgül ağırlığı ve özgül yüzey alanı (Chemical analysis, density and specific surface area of mineral additives)

\begin{tabular}{llllll}
\hline Bileşen & Birim & Yüksek Fırın Cürufu & Uçucu Kül & Silis Dumanı & Kireçtaş1 \\
\hline $\mathrm{CaO}$ & $\%$ & 39,8 & 6,66 & 1,48 & 51,4 \\
$\mathrm{SiO}_{2}$ & $\%$ & 32,8 & 47,4 & 74,7 & 2,96 \\
$\mathrm{Al}_{2} \mathrm{O}_{3}$ & $\%$ & 11,8 & 19,8 & 0,46 & 1,13 \\
$\mathrm{Fe}_{2} \mathrm{O}_{3}$ & $\%$ & 1,45 & 11,8 & 0,84 & 0,2 \\
$\mathrm{MgO}$ & $\%$ & 4,15 & 4,76 & 3,64 & 1,0 \\
$\mathrm{Na}_{2} \mathrm{O}$ & $\%$ & 0,51 & 0,57 & 0,85 & 0,03 \\
$\mathrm{~K}_{2} \mathrm{O}$ & $\%$ & 0,91 & 2,62 & 5,05 & 0,14 \\
$\mathrm{SO}_{3}$ & $\%$ & 2,06 & 1,86 & 2,48 & 0,03 \\
$\mathrm{Cr}_{2} \mathrm{O}_{3}$ & $\%$ & 0,02 & 0,13 & 2,83 & - \\
$\mathrm{TiO}_{2}$ & $\%$ & 0,63 & 0,88 & 0,63 & 0,07 \\
$\mathrm{~K} . K$. & $\%$ & 2,2 & 2,76 & 5,97 & 42,9 \\
\hline Özgül ağırlık & $\mathrm{g} / \mathrm{cm}^{3}$ & 2,8 & 1,99 & 2,44 & 2,72 \\
\hline Özgül yüzey alanı & $\mathrm{cm}^{2} / \mathrm{g}$ & 4982 & 3126 & 14000 & 2427 \\
\hline
\end{tabular}

Tablo 3. Mineral katkıların tane boyutu [ağırlıkça \%10, \%50 ve \%90’nın geçtiği elek göz açıklığı değerleri] (Particle size of mineral additives expressed as the passing through the sieve opening in percent 10, 50 and 90 by weight)

\begin{tabular}{llll}
\hline \multirow{2}{*}{ Mineral Katkı } & $\mathrm{d}(10)$ & $\mathrm{d}(50)$ & $\mathrm{d}(90)$ \\
\cline { 2 - 4 } & Elek aralı̆̆ $(\mu \mathrm{m})$ & Elek aralığ1 $(\mu \mathrm{m})$ & Elek aralığ $(\mu \mathrm{m})$ \\
\hline Uçucu Kül & 6,9 & 34,14 & 113,78 \\
Silis Dumanı & 1,06 & 10,84 & 29,16 \\
Yüksek Fırın Cürufu & 0,84 & 8,55 & 27,57 \\
Kireçtaşı & 4,95 & 66,51 & 125,61 \\
\hline
\end{tabular}


daha az oranda da amorf kuvars ve kuvars içerdiği görülmektedir. Uçucu kül ise ağırlıklı olarak kuvars ve feldspat'dan oluşmakta ve daha az oranda dolomit ve hematit içermektedir. Silis dumanına ait XRD piklerinin tamamının kuvars' in farklı mineral formlarına (tridimit, kristobalit, kuvars) ait olduğu ve bunun yanında ana bileşenlerden birisinin de amorf kuvars olduğu görülmektedir. Kireçtaşı tozunun ise ağırlıklı olarak kalsit mineralinden oluştuğu ancak bunun yanında az miktarda olsa kuvars ve dolomit bulunduğu belirlenmiştir.

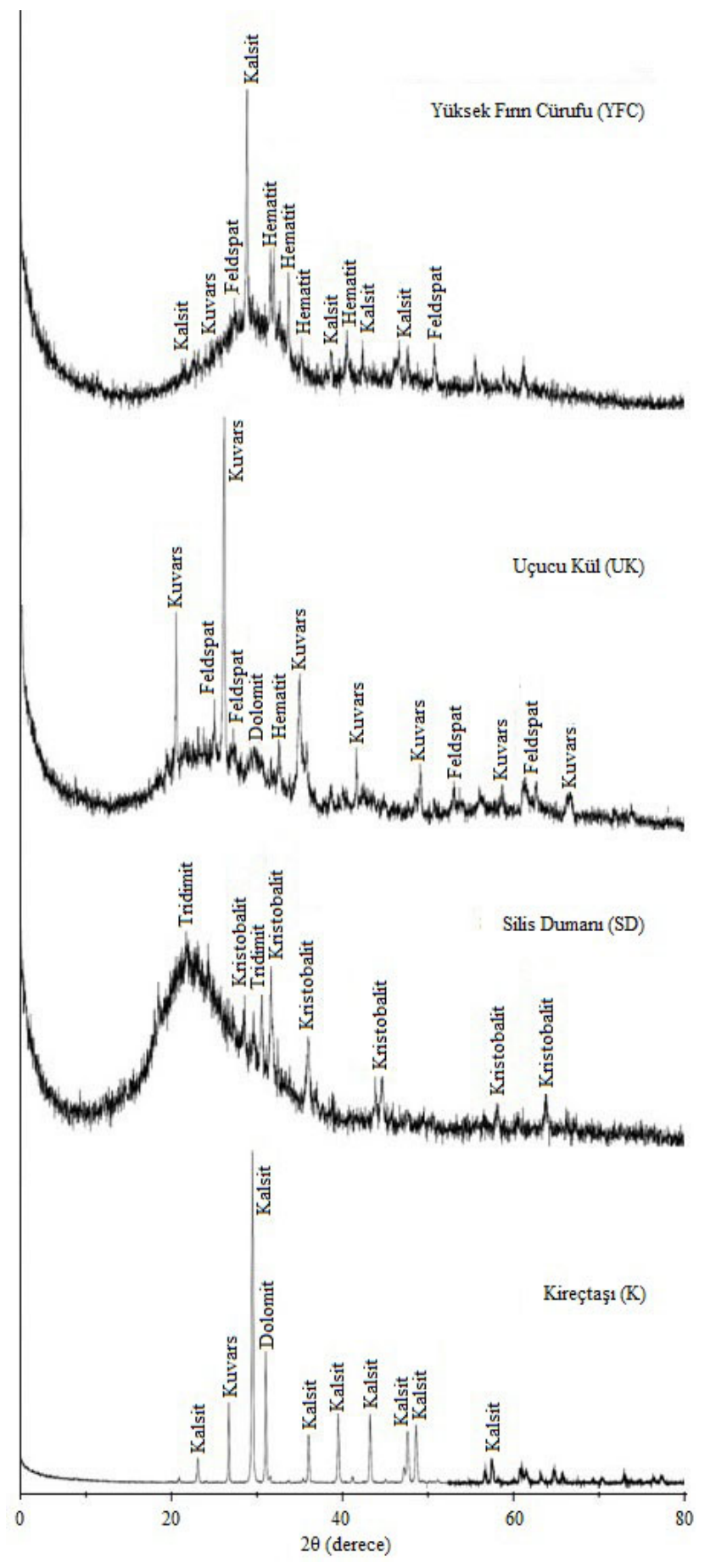

Şekil 4. Mineral katkıların XRD analizi (XRD analysis of mineral additives)

\subsection{Mineral Katkılı Epoksi Kompozit Numunelerinin Hazırlanması \\ (Preparation of Epoxy Composite Samples with Mineral Additive)}

Epoksi esaslı kompozit numuneleri, polimer bağlayıcı (epoksi reçinesi) içerisine dolgu (filler) olarak ağırlıkça \%0, $\% 10, \% 20, \% 30, \% 40$ ve $\% 50$ oranlarında farklı mineral katkılar katılarak üretilmiştir (Tablo 4). Silis dumanı çok yüksek yüzey alanına sahip bir atık ürün olduğundan (Tablo 2) homojen bir polimer harcı hazırlayabilmek en fazla $\% 30$ katkı oranına kadar mümkün olabilmiştir. Bunun üzerinde SD katkısı ile polimer harcında homojen bir dağılım elde edebilmek (iyi karıştırabilmek) mümkün olmamıştır. Epoksi ve mineral katkıdan oluşan her bir harç üretimi, oda sıcaklığında kapasitesi yaklaşık 5 lt olan harç mikseri (Şekil 5a) ile gerçekleștirilmiştir. Polimer harçların hazırlanmasında, ilk önce filler ile epoksi reçinenin A bileşeni miksere konularak 1 dakika boyunca kuru karıștırma yapıldı. Sonra bu karıșıma reçinenin sertleștirici görevini yapan B bileşeni ilave edildi ve bu üçlü karışımın dağılımı homojen bir hale gelene kadar 3 dakika karıştırıldı. Hazırlanan bu harç $10 \mathrm{~mm}$ uzunluğundaki teflondan yapılmış kaşık tipi kalıplara dökülmüştür (Şekil 5 b). Döküm işleminden 24 saat sonra mineral katkılı epoksi kompozit numuneleri kalıplardan alınmış ve 7 gün oda sıcaklığında bekletilerek temas açısı ölçümüne hazır hale getirilmiştir. Epoksi malzemeler nihai dayanımlarına 7 günde ulaşmaktadırlar (Tablo 1).

Tablo 4. Polimer harç karışım oranları (Polymer mortar mixing ratios)

\begin{tabular}{lcc}
\hline \multirow{2}{*}{ Mineral katk1, (\% Ağırlık) } & \multicolumn{2}{c}{ Epoksi Reçinesi } \\
\cline { 2 - 3 } & $\begin{array}{c}\text { A bileşeni } \\
\text { (\% Ağ.) }\end{array}$ & $\begin{array}{c}\text { B bileşeni } \\
\text { (\%Ağ.) }\end{array}$ \\
\hline 0 & 67,0 & 33,0 \\
10 & 60,0 & 30,0 \\
20 & 53,3 & 26,7 \\
30 & 46,7 & 23,3 \\
40 & 40,0 & 20,0 \\
50 & 33,3 & 16,7 \\
\hline
\end{tabular}

2.3. Damla Yayınım Yöntemi ile Temas Açısı Ölçümü (Contact Angle Measurement By Sessile Drop Method)

Kaşık tipi numuneler üzerinde "KSV Attension" marka ve "Theta Lite TL 101 Optical Tensiometer" cihazı (Şekil 6) ile Damla Yayınımı (Sessile Drop) yöntemi kullanılarak yüzey gerilimi (veya enerjisi) bilinen farklı polar (Saf su, Etilen glikol, Formamid) ve apolar (Diiodometan) sıviların (Tablo 5) her biri ile oda sicaklığında $\left(25 \pm 2^{\circ} \mathrm{C}\right)$ temas açısı ölçümleri gerçekleştirildi. Cihazın çalışma prensibi, yüzey gerilimi belli olan sıvının Hamilton mikro şırınga vasıtasıyla katı yüzeyine damlatılması ve bu damlanın katı yüzeyinde oluşturduğu temas açısının optik kamera ile hassas şekilde görüntüsünün alınması ve akabinde bu görüntü üzerinde dijital goniometre yardımıyla temas açısının ölçülmesine dayanır [34]. 


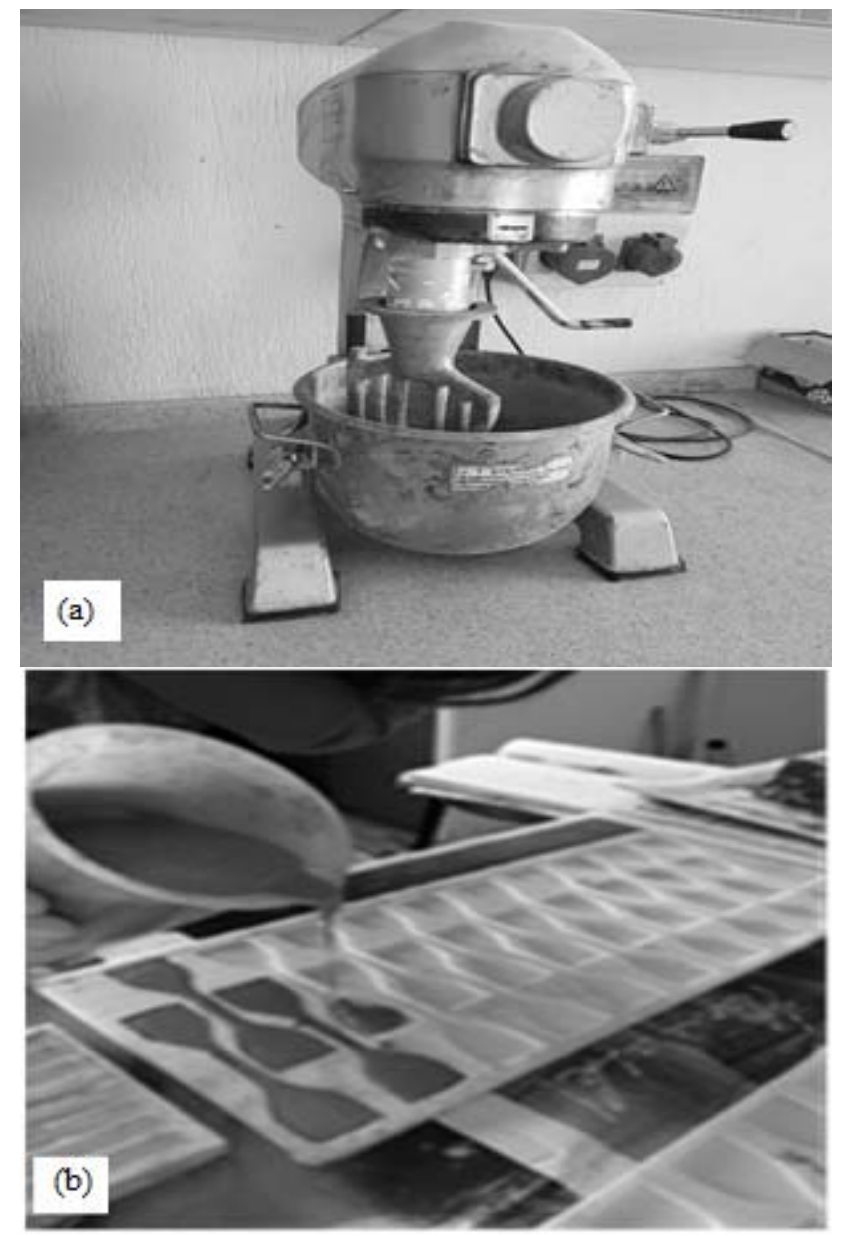

Şekil 5. a) Harç mikseri ve b) Hazırlanan epoksi harçların kalıplara konulması

((a) Mortar mixer (b)Casting of epoxy mortar into molds)

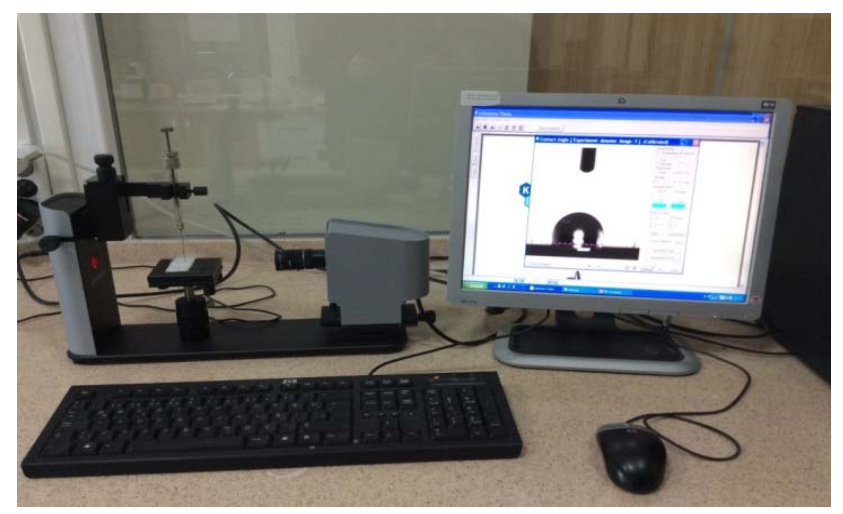

Şekil 6.Temas açısı ölçüm cihazı

(Contact angle measurement equipment)

\subsection{Yüzey Enerjisinin Hesaplanmast \\ (Calculation of Surface Energy)}

Yüzey enerjisi doğrudan deneysel bir ölçümle belirlenmesi mümkün olmayıp ancak temas açısı, sslanma 1sısı vb. veriler kullanılarak dolaylı yoldan bazı hesaplamalarla belirlenir. Temas açılarından elde edilen veriler cihaz tarafindan Fowkes-geometrik ortalama yaklaşımı 586 kullanılarak otomatik olarak $\left(\mathrm{mJ} / \mathrm{m}^{2}\right)$ olarak hesaplanmıştır $[34,35]$. Fowkes tarafindan önerilen geometrik ortalama yaklaşımında, katı yüzey enerjisi iki bileşen halinde incelenmiştir (Eş. 2) [36]. Bu bileşenler, dispersive $\left(\gamma^{\mathrm{d}}\right)$ ve polar $\left(\gamma^{\mathrm{P}}\right)$ enerji bileşenleridir. Fowkes tarafindan önerilen, katı yüzey enerjilerinin hesabında kullanılan aşağıdaki denklem, Young eşitliğinden türetilmiştir [36].

Tablo 5. Epoksi yüzey enerjisinin hesaplanmasında kullanılan polar ve apolar sıvılar ve yüzey enerjileri (Apolar and polar liquids used for calculation of surface energy of epoxy)

\begin{tabular}{|c|c|c|c|c|}
\hline \multirow[t]{2}{*}{ Siv1 } & \multirow[t]{2}{*}{$\begin{array}{l}\text { Kimyasal } \\
\text { Yapısı / Tipi }\end{array}$} & \multicolumn{3}{|c|}{$\begin{array}{l}\text { Yüzey Enerjisi } \\
(\text { Gerilimi }) \\
\text { Bileşenleri }\left(\mathrm{mJ} / \mathrm{m}^{2}\right)\end{array}$} \\
\hline & & $\gamma_{\mathrm{s}}$ & $\gamma_{S}^{d}$ & $\gamma_{\mathrm{S}}^{\mathrm{P}}$ \\
\hline $\mathrm{Su}$ & $\mathrm{H}_{2} \mathrm{O} /$ Polar & 72,8 & 21,8 & 51 \\
\hline Formamid & $\begin{array}{l}\mathrm{CH}_{3} \mathrm{NO} / \\
\text { Polar }\end{array}$ & 58 & 39 & 19 \\
\hline Etilen Glikol & $\begin{array}{l}\mathrm{HOCH}_{2} \mathrm{CH}_{2} \mathrm{O} \\
\mathrm{H} / \text { Polar }\end{array}$ & 48 & 29 & 19 \\
\hline Diiodometan & $\mathrm{CH}_{2} \mathrm{I}_{2} /$ Apolar & 50,8 & 50,8 & 0 \\
\hline
\end{tabular}

$\gamma_{\mathrm{S}}(1+\cos \theta)=2\left\lfloor\sqrt{\gamma_{\mathrm{S}}^{\mathrm{d}} \gamma_{\mathrm{K}}^{\mathrm{d}}}+\sqrt{\gamma_{\mathrm{S}}^{\mathrm{P}} \gamma_{\mathrm{K}}^{\mathrm{P}}}\right\rfloor$

Burada;

$\theta=$ Sıvı damlası ile katı yüzey arasında ölçülen temas açısı (Derece)

$\gamma_{\mathrm{s}}=$ Sıvının serbest yüzey enerjisi $\left(\mathrm{mJ} / \mathrm{m}^{2}\right)\left(\gamma_{\mathrm{S}}^{\mathrm{d}}\right.$ ve $\gamma_{\mathrm{S}}^{\mathrm{p}}$ değerlerinin toplamına eşittir)

$\gamma_{\mathrm{S}}^{\mathrm{d}}=$ Sıvının disperse serbest yüzey enerjisi $\left(\mathrm{mJ} / \mathrm{m}^{2}\right)$

$\gamma_{\mathrm{K}}^{\mathrm{d}}=$ Katının disperse serbest yüzey enerjisi $\left(\mathrm{mJ} / \mathrm{m}^{2}\right)$

$\gamma_{\mathrm{S}}^{\mathrm{P}}=$ Sivının polar serbest yüzey enerjisi $\left(\mathrm{mJ} / \mathrm{m}^{2}\right)$

$\gamma_{\mathrm{K}}^{\mathrm{p}}=$ Katının polar serbest yüzey enerjisi $\left(\mathrm{mJ} / \mathrm{m}^{2}\right)$

$\gamma_{\mathrm{K}}$ : Katının serbest yüzey enerjisi $\left(\mathrm{mJ} / \mathrm{m}^{2}\right)\left(\gamma_{\mathrm{K}}^{\mathrm{d}}\right.$ ve $\gamma_{\mathrm{K}}^{\mathrm{p}}$ değerlerinin toplamına eşittir)

\section{SONUÇLAR VE TARTIŞMALAR (RESULTS AND DISCUSSIONS)}

\subsection{Katkısız Epoksi Malzemesi Üzerinde Farklı Sivılarla Yapılan Temas Açısı Ölçümleri \\ (Contact Angle Measurements Performed on Epoxy Material without additive Using Various Liquids)}

Katkısız epoksi üzerinde farklı tür sıvılarla ölçülen temas açısı değerleri değerleri Şekil 7'de verilmiştir. Şekilden de görüldüğü üzere, polar karakterli yani yüzey enerjisinin $\gamma_{S}^{P}$ bileşeni nispeten daha yüksek sıvılar Tablo 5) olan su, etilen glikol ve formamid'in hidrofobik yüzeye sahip epoksi numunesi üzerinde oluşturduğu temas açısı ( $\Theta$ ) apolar sıv1 olan diĺodometan'a göre daha yüksektir. Bu durum esasen katkısız halde epoksi numunesinin hidrofobik özelliğini teyit etmektedir. Çünkü apolar diiodometan ile epoksi arasındaki van der walls diğer bir 
ifadeyle dispersiv etkileşimleri sistemde daha baskın hale gelmekte ve bu sebeple temas açısı diğer sıvilara göre daha düşük olmaktadır. Polar sıvıların temas açıları 80-102 arasında iken apolar özellikteki diiodometan için bu değer yaklaşık $58^{\circ}$ dir. Bu durum epoksinin hidrofobik özellikte olduğunu göstermektedir ve literatürde epoksinin su ile yaptığı temas açısı değerinin epoksinin kimyasal yapısına da bağlı olarak $90-110^{\circ}$ arasında değiștiği bilgisini desteklemektedir [37]. Epoksiler, kimyasal yapılarındaki, polar, apolar ve hidrojen bağı yapabilecek atom grupları sayesinde sıv1 molekülleriyle etkileşime girebilirler. Özellikle su, etilen glikol ve formamid ile hidrojen bağ oluşturabilirler [28].

\subsection{Mineral Katkıların Epoksinin Islanmazlı̆̆ına Etkisi (Effect of Mineral Additives on Non-Wettability of Epoxy)}

Şekil 8'de epoksinin 1slanmazlık bir başka ifadeyle su sevmezlik yani hidrofobisite özelliğinin bir göstergesi olan su ile temas açısının, mineral katkı türleri ve katkı miktarı ile nasıl değiştiği görülmektedir. Şekilden de açıkça görüldüğü üzere katkısız epoksi numunesinin su ile temas açısına en çok etki eden katkı türünün kireçtaşı olduğu ve $\% 10^{\prime}$ luk kalsit ilavesiyle, $102^{\circ}$ olan temas açısının keskin bir düşüşle $50^{\circ}$ 'ye indiği, ancak bu orandan sonraki kalsit ilavelerinin temas açısında tedrici bir azalmaya sebep olduğu ve $\% 50$ katkı oranında yaklaşık $37^{\circ}$ ye düştüğü görülmektedir. Yüksek firın cürufu ile silis dumanının temas açısı üzerinde hemen hemen aynı etkiyi gösterdiği ve kalsite oranla temas açısını daha az düşürdüğü görülmektedir. Epoksi temas açısı bu iki katkının \%10'luk ilavesiyle 75 - 78 dereceye düştüğü, ancak bundan sonraki ilavelerin temas açısına pek etki etmediği görülmektedir. Epoksinin temas açısına en az etki eden mineral katkı olan uçucu kül'ün \%20'ye kadar ilavesiyle temas açısında çok az bir azalma olduğu ve açının $102^{\circ}$ 'den yaklaşık $96^{\circ}$ 'ye düştüğü, daha yüksek katkı oranının ise temas açısını biraz daha fazla düşürdüğü ve $\% 50$ katkıda $73^{\circ}$ olduğu belirlenmiştir. Şekil 8'e genel olarak bakıldığında katk1 miktarı olarak dikkat çeken katkı miktarının \%10 değeri olduğu, bu oranın üzerinde (uçucu kül hariç) mineral katkıların epoksinin hidrofobisitesine ciddi bir etkisinin

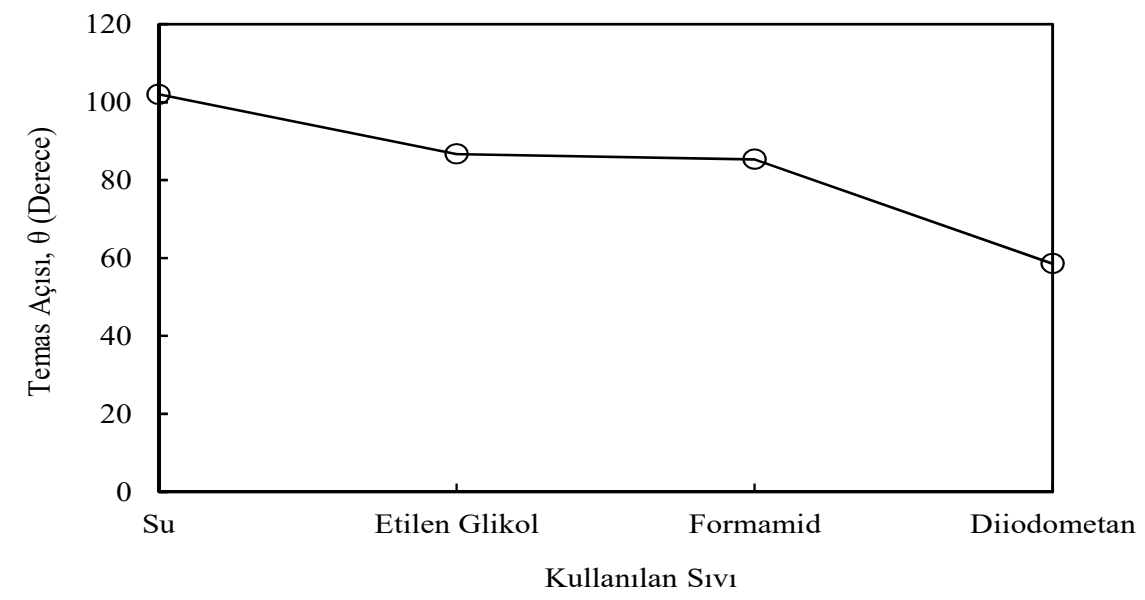

Şekil 7. Farklı sıvılarla katkısız epoksi üzerinde ölçülen temas açıları (Contact angles measured on epoxy without additive using by various liquids)

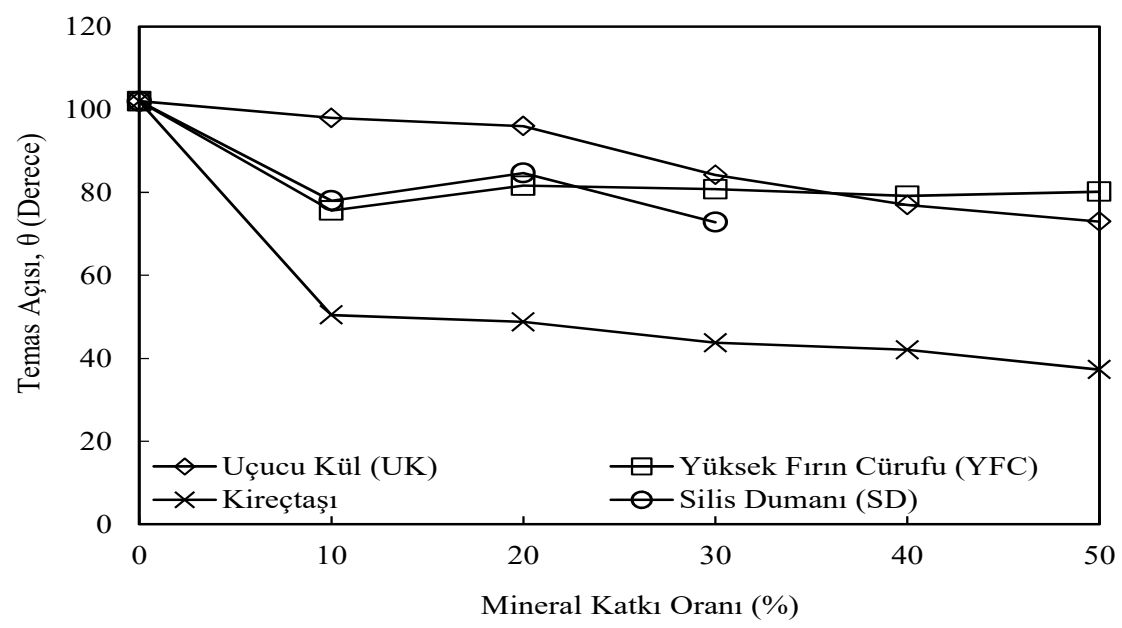

Şekil 8. Epoksi malzemenin su ile temas açısına mineral katkı çeşidinin ve katkı oranının etkisi (The effect of mineral type and amount on contact angle of epoxy with water) 
olmadığ1 görülmektedir. Şekil 9'da katkılı ve katkısız epoksilerin su ile temas açılarının fotoğraf görüntüleri verilmiştir. Buna göre mineral katkıların epoksinin 1slanmazlık özelliğini az ya da çok olumsuz etkilediği ve bu etkinin büyükten küçüğe şu şekilde olduğu görülmektedir: Kireçtaşı $>$ Yüksek Fırın Cürufu $=$ Silis Dumanı $>$ Uçucu Kül. Mineral katk1 türlerine göre epoksinin 1slanmazlık özelliğinin farklı etkilenmesi elbette bu mineral katkıların mineral ve kimyasal içeriklerinin ve fiziksel özelliklerinin farklı olmasından kaynaklanmaktadır. Literatürden de bilindiği üzere minerallerin hidrofilik/hidrofobik karakterleri birbirinden farklıdır [38,39]. Talk, molibden sülfür ve kömür gibi bir kaçı hariç minerallerin büyük çoğunluğu hidrofilik karakterdedir. Bu nedenle de mineral katkılarına paralel olarak hidrofobik malzemelerin su ile temas açısının daha da azalması beklenir ki bu çalışmada da benzer sonuçlar elde edilmiştir. Yani mineral katkısı su ile temas açısını azaltmaktadır. Bunun da sebebi mineral katkılı epoksinin hidrofobik karakterinin azalması ile birlikte polar yapıdaki su damlası ve katı yüzey arasındaki polar (asit-baz) etkileşimlerin artmasıdır. Makalenin giriş kısmında da ifade edildiği üzere epoksinin sslanmazlık özelliğine doğal mineral katkıların etkisine ilişkin literatürde sadece bir çalışma [10] yapılmış olup, silikanın epoksinin temas açısına etkisi incelenmiştir. Sonuçta \%1020 arasında silika yani kuvars ilavesinin epoksinin temas açısına bir etkisinin olmadığını belirlemişlerdir. Ancak, bunun aksine bu çalışmada kullanılan silis dumanının epoksinin temas açısını önemli seviyede azalttığ belirlenmiştir. Bu durum kullanılan mineral maddelerin her ne kadar hemen hemen aynı kimyasal içeriğe $\left(\mathrm{SiO}_{2}\right)$ sahip olsalar da, mineralojik içerik bakımından birbirinden farklı1ık göstermesinden kaynaklanıyor olabilir. Bilindiği üzere silis dumanındaki amorf kuvars içeriği, silikaya göre çok daha yüksektir.

\subsection{Mineral Katkıların Epoksinin Yüzey Enerjisine Etkisi (Effectc os Mineral Additives on Surface Energy of Epoxy)}

Şekil 10'da mineral katkı türü ve miktarının epoksinin yüzey enerjisine etkisini gösteren eğriler verilmiştir. Şekilde de açıkça görüldügü gibi yüzey enerjisini en fazla etkileyen katkı türü kireçtaşı ve en az etkileyen uçucu kül olup, diğer iki katkının (yüksek firın cürufu ve silis dumanı) davranışı hemen hemen aynıdır. Bu durum su ile temas açısı verileriyle de birebir uyumludur. $23 \mathrm{~mJ} / \mathrm{m}^{2}$ olan yüzey enerjisi \%10 kireçtaşı katkısında nispeten hızlı bir artışla yaklaşık $40 \mathrm{~mJ} / \mathrm{m}^{2}$,ye yükselmekte ve bundan sonraki katk1 miktarlarında tedrici bir artış olmakta ve \%50 katk1 miktarında $48 \mathrm{~mJ} / \mathrm{m}^{2}$, ye çıkmaktadır. \%10 yüksek firın cürufu ve silis dumanı katkısının epoksinin yüzey enerjisini yaklaşık $27 \mathrm{~mJ} / \mathrm{m}^{2}$ 'ye çıkarmakta ve bundan sonraki katk1 oranlarında önemli bir değişiklik olmadığı görülmektedir. Uçucu kül'ün ise $\% 20$ oranına kadar epoksi yüzey enerjisine bir etkisinin olmadığı ancak bu orandan sonra kısmi bir artış olduğu ve \%50 oranında uçucu kül katkısıyla epoksinin yüzey enerjisinin $29 \mathrm{~mJ} / \mathrm{m}^{2}$ 'ye çıktığ görülmektedir. Elde edilen bu sonuçlar literatürden de iyi bilindiği gibi malzemelerin hidrofobisite ile yüzey enerjisi arasındaki genel ilişkiyi desteklediği açık bir şekilde görülmektedir [18]. Daha açık ifade edilecek olursa epoksinin hidrofobik karakteri mineral katkı türü ve miktarına bağlı olarak az ya da çok azalmakta ve buna paralel olarak da epoksinin yüzey enerjisi katkı türü ve miktarına bağlı olarak az ya da çok artmaktadır. Epoksinin hidrofobik karakterini olumsuz yönde en çok etkileyen kireçtaşı, aynı zamanda yüzey enerjisini de en çok artıran katkı olmuştur.
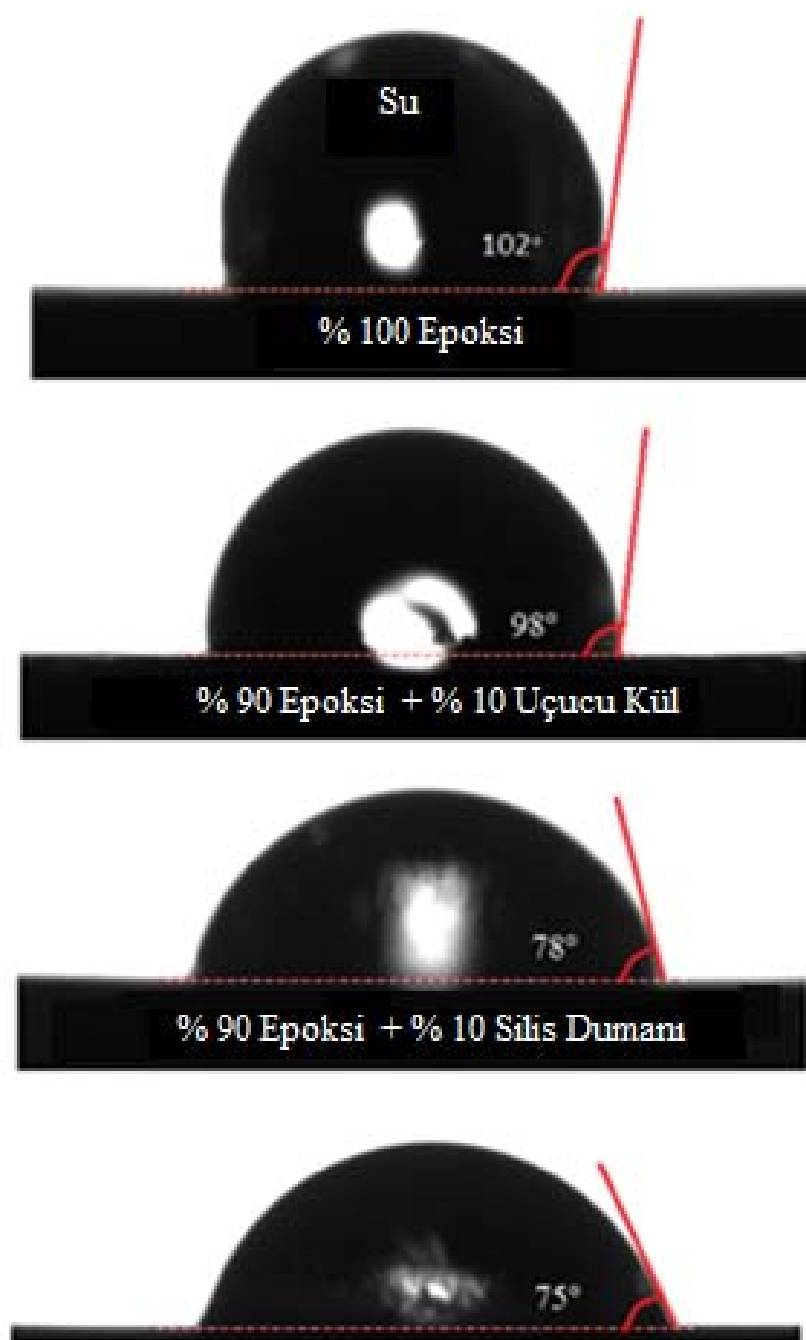

$\% 90$ Epoksi $+\% 10$ YüksekFrnn Cürufu

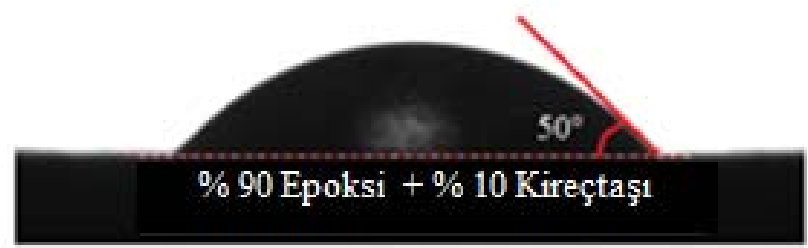

Şekil 9. Katkısız ve ağırlıç̧a \%10 mineral katkılı epoksi malzemesinin su damlası ile yaptığı temas açılarının fotoğrafları

(Photographs of contact angles measured between water drop and epoxy materials without and with $10 \% \mathrm{wt}$ mineral additive) 


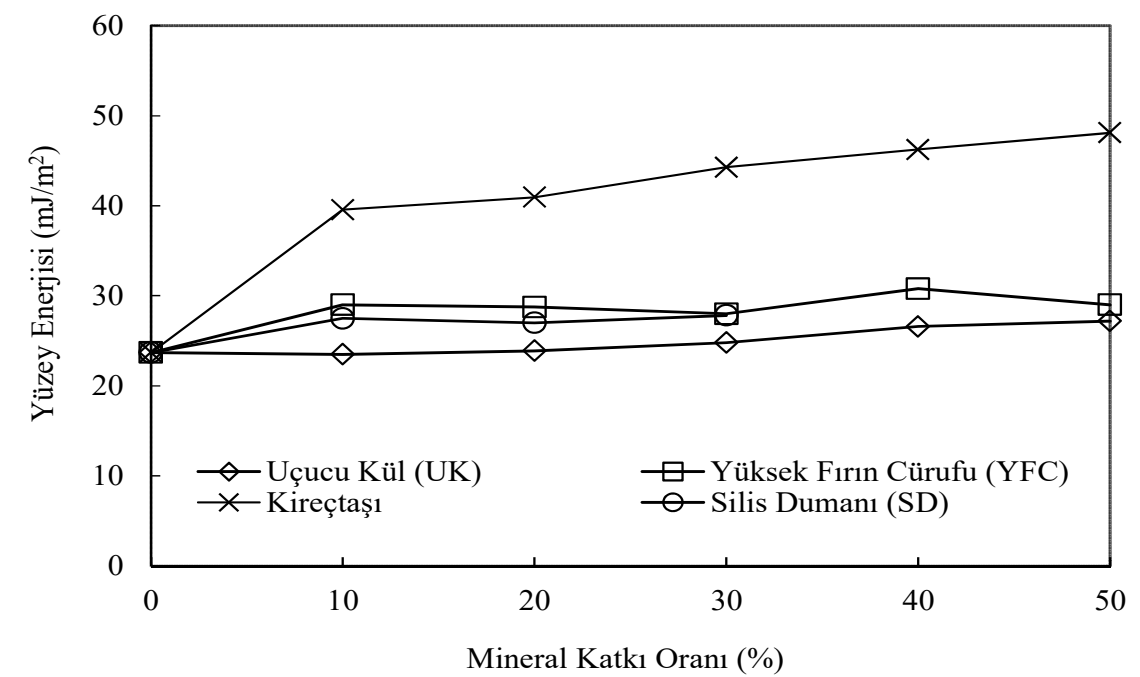

Şekil 10. Epoksi malzemenin yüzey enerjisine mineral katkı çeşidinin ve katkı oranının etkisi (Effect of mineral type and amount on surface energy of epoxy)

\section{SONUÇLAR (CONCLUSIONS)}

$\mathrm{Bu}$ çalışmada farklı mineral katkılarının epoksi reçine ile karıştırılması sonucu elde edilen zemin kaplama malzemesinin farklı sıvılar ile ölçülen temas açısı verileri kullanılarak yüzey özelliklerinde (hidrofobisitesi ve yüzey enerjisi) meydana gelen değişiklikler incelenmiştir. Buna göre; Katkısız halde iyi bir hidrofobik karaktere sahip olan epoksi'nin, mineral katkılarla birlikte bu özelliği katkı türü ve miktarına bağlı olarak kısmen veya önemli ölçüde azalmaktadır. Su ile temas açısını (hidrofobik karakterini) en çok azaltan katkı türü kireçtaşı iken en az azaltan uçucu kül olmuştur. Katkısız halde epoksinin su ile temas açısı $102^{\circ}$ iken, $\% 30$ kireçtaşı katkısı ile $43^{\circ}$ 'ye ve \%30 uçucu kül katkısıyla $84^{\circ}$ 'ye düşmektedir. Uçucu kül hariç diğer mineral katkılar için \%10 katk1 oranından sonraki katk1 miktarının epoksi hidrofobik karakterini azaltmada ve yüzey enerjisini artırmada önemli bir etkisinin olmadığ1 görülmüştür. Katkısız epoksinin yüzey enerjisi $23 \mathrm{~mJ} / \mathrm{m}^{2}$ iken mineral katkı türü ve miktarına bağlı olarak bu değer az ya da çok artmaktadır. Temas açısı verilerine uygun olarak epoksinin yüzey enerjisini en çok artıran (hidrofobik karakterini en çok azaltan) katkı türü kalsit iken en az artıran uçucu kül olmuştur.

Epoksi esaslı zemin kaplama malzemesinin sahip olduğu hidrofobik karakterini olumsuz yönde pek fazla etkilemeden kullanılabilecek en uygun mineral katkının uçucu kül olduğu ve katkı oranı açısından \%20'yi geçmemesi gerektiği söylenebilir.

\section{TEŞEKKÜR (ACKNOWLEDGEMENT)}

$\mathrm{Bu}$ çalışma 114M155 kodlu ve "Zemin Kaplamada Kullanılan Epoksi Reçinesiyle Yüksek Oranda Mineral Katkı Kullanımının Araştırılması” başlıklı Tübitak-3001 projesi kapsamında gerçekleştirilmiş olup, katkılarından dolayı Tübitak’a teşekkür ederiz.

\section{KAYNAKLAR (REFERENCES)}

1. Karaman M., Uçar T., Enhanced mechanical properties of low-surface energy thin filmsby simultaneous plasma polymerization of fluorine and epoxy containing polymers" Appl. Surf. Sci., 362, 210-216, 2016.

2. Arukalam I.O., Oguzie E.E., Li Y., Fabrication of FDTS-modified PDMS-ZnO nanocomposite hydrophobic coating with anti-fouling capability for corrosion protection of Q235 steel, J. Colloid Interface Sci., 484, 220-228, 2016.

3. Gnedenkov S.V., Sinebryukhov S.L., Egorkin V.S., Vyaliy I.E, Wettability and electrochemical properties of the highly hydrophobic coatings on PEO-pretreated aluminum alloy, Surf. Coat. Technol., 2016. (in press, doi: 10.1016/j.surfcoat.2016.11.036)

4. Gao Z., Zhai X., Liu F., Zhang M., Zang D., Wang C., Fabrication of $\mathrm{TiO} 2 / \mathrm{EP}$ super-hydrophobic thin film on filter papersurface, Carbohydr. Polym, 128, 24-31, 2015.

5. Asano H., Shiraishi Y., Development of paper-based microfluidic analytical device for iron assay using photomask printed with $3 \mathrm{D}$ printer for fabrication of hydrophilic and hydrophobic zones on paper by photolithography, Anal. Chim. Acta, 883, 55-60, 2015.

6. Leja J., Surface Chemistry of Froth Flotation, Plenum Press, New York, 1982.

7. Hiemenz P.C., Principles of Colloid and Surface Chemistry, 2nd Ed.; Marcel Dekker Inc., New York, 1986.

8. Gönül N., Süspansiyon ve Emülsiyon Teknolojisi, Ankara Üniversitesi Eczacılık Fakültesi Eczacılık Teknolojisi Bölümü, Ankara, 2000.

9. Hölck O., Bauer J., Wittler O., Michel, B., Wunderle B., Comparative characterization of chip to epoxy interfaces by molecular modeling and contact angle 
determination, Microelectron. Reliab., 52, 7, 12851290, 2012.

10. Syakur, A., Berahim, H., Rochmadi, T., Hydrophobic Contact Angle and Surface Degradation of Epoxy Resin Compound with Silicon Rubber and Silica, Electrical and Electronic Eng., 2, 5, 284-291, 2012.

11. Le N.L., Nunes S.P., Materials and membrane technologies for water and energy sustainability, Sustainable Mater. and Technol., 7, 1-28, 2016.

12. Chakradhar R.P.S., Dinesh Kumar V., Rao J.L., Basu, B.J. Fabrication of superhydrophobic surfaces based on $\mathrm{ZnO}-\mathrm{PDMS}$ nanocomposite coatings and study of its wetting behaviour, Appl. Surf. Sci., 257, 85698575, 2011.

13. Lung C.Y.K., Matinlinna, P. Surface Pretreatment Methods and Silanisation in Handbook of Oral Biomaterials, Ed. Jukka P. Matinlinna; CRC Press, Boca Raton, 2015.

14. Shang H.M., Wang,Y., Takahash1 K., Cao G.Z., LI, D., Xia Y. N. Nanostructured superhydrophobic surfaces, J. Mater. Sci., 40, 3587 - 3591, 2005.

15. A.W. Adamson, Physical Chemistry of Surfaces, John Wiley \& Sons Inc., Los Angeles, 697, 1976.

16. Miller C.A.P. Neogi Interfacial Phenomena (Equilibrium and Dynamic Effects), Marcel Dekker Inc., New York, 1985.

17. Van Giessen A.E., Bukman D.J., Widom B., Contact Angles of Liquid Drops on Low-Energy Solid Surfaces, J. Colloid Interface Sci., 192, 257-265, 1997.

18. Kwok D.Y., Neumann A.W., Contact angle measurement and contact angle interpretation, Adv. Colloid Interface Sci., 81, 167-249, 1999.

19. Yildırım İ., Surfaces Free Energy Characterizastion Of Powders, PhD Thesis, Virginia Polytechnic Institute and State University, Mining and Minerals Engineering, 2001.

20. Terada K., Yonemochi E., Physicochemical properties and surface free energy of ground talc, Solid State Ionics, 172, 459-462, 2004.

21. Israelachvili J.N., Intermolecular and Surface Forces, Academic Press, London, 1995.

22. Awalellu K.A., A Review on Properties and Applications of Polymer Matrix Composites, Int. J. Res. Sci. Innovation, 3, IA, 53-55, 2016.

23. Uygunoğlu T., Güneş İ., Ersoy B., Evcin A., Effect of Mineral Admixture Type on Rheological Properties of Polymeric Self-Consolidating Mortar, Journal of the Faculty of Engineering and Architecture of Gazi University, 32 (4), 1365-1377, 2017.

24. Alagar M., Velan T.V.T., Kumar A.A., Mohan V., Synthesis and Characterization of High Performance Polymeric Hybrid Siliconized Epoxy Composites for Aerospace Applications, Mater. Manuf. Processes, 14, 1, 67-83, 1999.

25. Chrazan K.L., Perfromance of hydrophobic epoxy insulators under indutrial pollution", XVth Int. Symposium on High Voltage Eng., University of Ljubljana, Slovenia, 2007.
26. Friedrich D., Luible A., Investigations on ageing of wood-plastic composites for outdoor applications: A meta-analysis using empiric data derived from diverse weathering trials, Constr. Build. Mater., 124, 11421152, 2016.

27. Bazant P., Munster L., Machovsky M., Sedlak J., PastorekM., Kozakova Z., Kuritka I., Wood flour modified by hierarchical $\mathrm{Ag} / \mathrm{ZnO}$ as potential filler for wood-plastic composites with enhanced surface antibacterial performance, Ind. Crop. and Prod, 62, 179-187, 2014.

28. Abbasiana A., Ghaffariana S.R., Mohammadia N., Fallahi, D., The contact angle of thin-uncured epoxy films: thickness effect, Colloids Surf., A, Physicochem.Eng. Aspects, 236, 133-140, 2004.

29. Chibowski, E., Hołysz, L., Terpiłowski, K., Jurak, M. Investigation of super-hydrophobic effect of PMMA layers with different fillers deposited on glass support, Colloids Surf., A 291, 181-190, 2006.

30. Atta A.M., Al-Lohedan H.A., Ezzat A.O., Al-Hussain S.A. Characterization of superhydrophobic epoxy coatings embedded bymodified calcium carbonate nanoparticles, Prog. Org. Coat., 101, 577-586, 2016.

31. Bikkina, P.K. "Contact angle measurements of $\mathrm{CO} 2-$ water-quartz/calcite systems in the perspective of carbon sequestration", Int. J. Greenhouse Gas Control, 5 (5), 1259-1271, 2011.

32. Ersoy B., Kavas T., Evcin A., Başpınar S., Sarışık A., Önce $\mathrm{G}$. The effect of $\mathrm{BaCO} 3$ addition on the sintering behavior of lignite coal fly ash, Fuel, 87, 2563-2571, 2008.

33. Augustson C., NM Epoxy Handbook, Nils Malmgren AB, Sweeden, 2004.

34. Arsoy Z., Talkın Yüzey Özelliklerine Öğütmenin Etkisi, Yüksek Lisans Tezi, Afyon Kocatepe Ünversitesi, Fen Bilimleri Enstitüsü, Afyonkarahisar, 2014.

35. Shen W., Filonanko Y., Truong Y. Parker I.H., Brack N., Pigram P. and Liesegang J., Contact angle measurement and surface energetic of sized and unsized paper, Colloids Surf., A , Physicochem. Eng. Aspects, 173, 117-126, 2000.

36. Fowkes F.M, Acid-base interactions in polymer adhesion: physicochemical aspects of polymer surfaces, Ed K.L. Mital, Plenum Press, New York, 1983.

37. Pilling J., Chrzan K., Hofmann J., Baersch R. Artficial aging of polymer insulation surface in a clean fog chamber and its evaluation, 8th Int. Symposium on High Voltage Engineering ISH, Yokohama, 47.04. 1993.

38. Gence N. Wetting behavior of magnesite and dolomite surfaces, Appl. Surf. Sci., 252, 10, 15, 3744-3750, 2006.

39. Shrimali K., Jin J., Vaziri Hassas B., Wang X., Miller Jan D., The surface state of hematite and its wetting characteristics, J. Colloid Interface Sci., 477, 1,16-24, 2016. 